\title{
Production of the Calcium Fluoride From Solid and Iiquid Wastes of Aluminum Production Process
}

\author{
Anatoly N. Baranov ${ }^{a}$, Lyudmila V. Gavrilenko ${ }^{\text {b*, }}$ \\ Anton V. Morenkoc ${ }^{c}$, Aleksander A. Gavrilenko ${ }^{d}$, \\ Ekaterina V. Timkina ${ }^{\mathrm{a}}$ and Pavel A. Yakushevich ${ }^{\mathrm{d}}$ \\ ${ }^{a}$ National Research Irkutsk State Technical University \\ 83 Lermontov, Irkutsk, 664074, Russia \\ ${ }^{b}$ United Company RUSAL Engineering \& Technology Centre LLC \\ Bratsk, 665716, Russia \\ ${ }^{c}$ RUSAL Global Management, CSC \\ 40 Pogranichnikov Str., Krasnoyarsk, 660111, Russia \\ ${ }^{d}$ RUSAL Bratsk JSC \\ Bratsk, 665716, Russia
}

Received 21.02.2015, received in revised form 03.03.2015, accepted 30.03.2015

A technology for the regeneration of fluorine to produce calcium fluoride from a saturated solution of gas purification had developed. Investigated the optimal conditions for the synthesis of calcium fluoride gas cleaning solutions. Production of calcium fluoride will reduce the cost of secondary cryolite, and the purchase of a primary $\mathrm{CaF}_{2}$ to $80 \%$. The laboratory study on extraction of fluoride from solid waste leaching process followed by obtaining secondary fluorides. Waste technology will reduce the waste of aluminum production, to receive income from the use of recycled materials and implementation of carbon concentrate in other industries.

Keywords: aluminum, fluoride, liquid and solid waste, calcium fluoride, cryolite, secondary raw materials, the carbon concentrate.

(C) Siberian Federal University. All rights reserved

* Corresponding author E-mail address: Lyudmila.Gavrilenko@rusal.com 


\title{
Производство фторида кальция
}

\section{из твердых и жидких отходов}

\section{процесса получения алюминия}

\author{
А.Н. Баранов ${ }^{\mathrm{a}}$, Л.В. Гавриленко ${ }^{\sigma}$, А.В. Моренко \\ А.А. Гавриленко ${ }^{г}$ Е.В. Тимкина ${ }^{a}$, П.А. Якушевич ${ }^{\mathrm{r}}$ \\ ${ }^{a}$ Иркутский государственный технический университет \\ Россия, 664074, Иркутск, Лермонтова, 83 \\ ${ }^{\circ} О О О$ «РУСАЛ Инженерно-технологический центр» \\ Россия, 665716, Братск

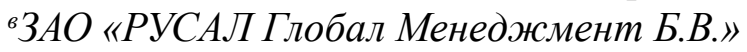 \\ Россия, 660111, Красноярск, Пограничников, 40 \\ 'ОАО «РУСАЛ Братск» \\ Россия, 665716, Братск
}

\begin{abstract}
Для регенеращии фтора разработана технология получения фторида кальиия из насыщенных растворов газоочистки. Исследованы и определены оптимальные условия процесса синтеза фторида кальичя. Производство СаF2, полученного из растворов газоочистки, позволило снизить себестоимость 1 т вторичного криолита и закупку свежего фторида кальция на $80 \%$. Результат по регенерации фтора из вторичных жидких отходов положил начало научному поиску по извлечению его из твердых отходов. Проведены лабораторные исследования по извлечению фтора из твердых отходов способом выщелачивания с последующим получением вторичных фторидов, пригодных для использования в процессе электролиза алюминия. Безотходная технология позволит снизить образование отходов алюминиевого производства, получить доход от использования вторичного сырья в процессе электролиза и реализации углеродного концентрата в другие отрасли промышленности.
\end{abstract}

Ключевые слова: алюминий, фтор, жидкие и твердые отходы, фторид кальция, вторичный криолит, вторичное сырьё, углеродный концентрат.

Ежегодно на Братском алюминиевом заводе образуется 40 тыс. т твердых фторсодержащих отходов. 30 \% от указанного объема составляют хвосты флотации (до 12 тыс. т/год), 15 \% - шламы газоочистки (до 7 тыс. т/год), 30 \% - пыль электрофильтров (12 тыс. т/год) и отработанная футеровка электролизеров - $25 \%$ (10 тыс. т/год). Содержание фтора в этих отходах колеблется от 9 до 26 \%. В результате шламовые поля завода интенсивно заполняются и, как следствие, требуют постоянной чистки или реконструкции. Помимо этих затрат существует ряд обязательных экологических платежей за размещение отходов. При этом экологическая напряженность в регионе не снижается, а с каждым годом растет, что требует незамедлительного решения по разработке и внедрению безотходной технологии на заводах алюминиевого производства [1].

Классическая схема производства вторичного криолита - это флотация угольной пены с получением флотационного криолита и переработка растворов мокрой газоочистки с получением регенерационного криолита. Но эти процессы незамкнутые: их побочными продуктами являются хвосты флотации и шламы газоочистки, которые и складируются на шламонакопителях. Проблеме обезвреживания и использования фторсодержащих отходов и возвращения

$$
-469-
$$


фтора в производство уделяется большое внимание [2]. В последние годы для повышения производительности производства алюминия применяют кислые электролиты с криолитовым отношением от 2.2 до 2.4, что влечет за собой увеличение концентрации фтористого водорода в отходящих газах электролизного производства, поступающих в систему газоочистки.

Вторичный криолит, полученный из насыщенных техногенных растворов, имеет высокое криолитовое отношение, равное 3 и более, что требует дополнительного расхода фторида алюминия для корректировки состава электролита. Это обстоятельство привело к профициту объема регенерационного криолита около 40 \% от годового выпуска вторичного сырья.

Результаты исследований показали, что получение вторичного сырья - фторида кальция из растворов газоочистки принципиально возможно $[2,3]$. При этом наблюдается увеличение концентрации $\mathrm{Na}_{2} \mathrm{CO}_{3}$ в отработанном растворе на 65-67 \% за счет образования каустической соды и разрушения бикарбоната натрия.

Техническими результатами являются: извлечение фтора из растворов газоочистки с получением фторида кальция, который востребован в процессе электролиза, обогащение раствора содой кальцинированной после обработки гидроокисью кальция с последующим его использованием в системе газоочистки. С 2011 г. в ОАО «РУСАЛ Братск» начато производство фторида кальция в промышленном масштабе. В 2012 г. выпуск вторичного фторида кальция в пересчете на свежее сырье составил 401 т, что подтверждено снижением расхода СaF2 в электролизном производстве. При этом в 2012 г. снижен выпуск регенерационного криолита на 252 т, что повлекло уменьшение расхода дорогостоящего сырья на производство, а именно соды каустической и гидроокиси алюминия. Благодаря внедрению технологии по производству фторида кальция экономический эффект в 2012 г. составил около 12 млн руб.

После фильтрации смешанной пульпы и сушки готовый продукт - вторичный криолит с повышенной концентрацией $\mathrm{CaF}_{2}$ - отгружается в корпуса электролиза. Опытным путем установлено, что расход гашеной извести при производстве фторида кальция из растворов газоочистки соответствует 1 т на 1 т $\mathrm{CaF}_{2}$. По результатам проведенных опытно-промышленных испытаний установлено, что извлечение фтора из осветленного раствора газоочистки во фторид кальция составляет 74-77 \% [4], что подтверждено технико-экономическими показателями производства вторичного сырья.

Для полного обеспечения процесса электролиза фторидом кальция собственного производства требуется расширение аппаратурно-технологической схемы получения $\mathrm{CaF}_{2}$ и внедрение локальной автоматизации по контролю и управлению процессами, чем в настоящее время занимается ООО «РУСАЛ ИТЦ» совместно со специалистами ОАО «РУСАЛ Братск».

Технология производства фторида кальция из растворов газоочистки позволила начать поиск по извлечению фтора из твердых отходов алюминиевого производства с получением вторичных фторидов и углеродсодержащего концентрата для внедрения безотходной технологии на заводе.

Существует множество разнообразных способов и технологий переработки фторсодержащих отходов. В основе способа, предложенного нами, лежит метод выщелачивания фтора из твердых отходов алюминиевого производства, который в ходе серий экспериментов показал достаточно высокую эффективность. Были проведены исследования по извлечению фтора из хвостов флотации и угольной футеровки способом выщелачивания в лабораторных условиях, 
Таблица 1. Физико-химическая характеристика твердых отходов алюминиевого производства

\begin{tabular}{|l|c|c|c|c|c|c|c|}
\hline \multirow{2}{*}{\multicolumn{1}{|c|}{ Материал }} & \multicolumn{7}{|c|}{ Химический состав, \% вес } \\
\cline { 2 - 9 } & $\mathrm{F}$ & $\mathrm{Al}$ & $\mathrm{Na}$ & $\mathrm{SiO}_{2}$ & $\mathrm{Fe}_{2} \mathrm{O}_{3}$ & $\mathrm{C}$ & $\mathrm{SO}_{4}$ \\
\hline Хвосты флотации & $6-11$ & $2-4$ & $3-5$ & $0,1-0,5$ & $0,1-0,5$ & $75-85$ & $0,5-2,5$ \\
\hline Угольная футеровка & $8-15$ & $8-11$ & $10-12$ & $1.5-1.8$ & $1.4-3.1$ & $45-50$ & $0.5-1.2$ \\
\hline
\end{tabular}

так как применяемая технология контрольной стадии флотации в промышленных условиях имеет низкую эффективность, а сбыт угольной футеровки в производство черной металлургии - непостоянный характер.

В лаборатории ИрГТУ авторами статьи были отобраны и проанализированы исходные пробы фторуглеродсодержащих отходов (табл. 1), проведены эксперименты по подбору оптимальных условий по выщелачиванию фторидов из хвостов флотации угольной пены и угольной футеровки. Полученные углеродные материалы после отмывки подвергались химическому анализу, определялся их фазовый состав.

Как видно из табл. 1, хвосты флотации и угольная футеровка содержат значительное количество F, что является важным фактором.

Способ выщелачивания заключается в извлечении фтора из твердых фторуглеродсодержащих отходов электролитического производства алюминия в водный раствор неорганических кислот и щелочей. Нами был проведен подбор оптимальных условий с использованием водных растворов серной кислоты $\left(\mathrm{H}_{2} \mathrm{SO}_{4}\right)$ и щелочи натрия $(\mathrm{NaOH})$ различной концентрации при разных температурах, исследована кинетика выщелачивания и перевода фтора в раствор из хвостов флотации и угольной футеровки.

Наиболее высокая эффективность извлечения фтора в раствор была достигнута в щелочной среде с концентрацией $\mathrm{NaOH} 2 \%$ при температуре от 65 до $80^{\circ} \mathrm{C}$, что отражено на рис. 1,2 .

Оптимальные параметры эксперимента: температура процесса не более $80{ }^{\circ} \mathrm{C}$, время выщелачивания не более 30 мин, отношение Ж : Т в пределах (8-6):1.

Как видно на рис. 1 и 2, извлечение фтора в раствор щелочи достаточно высоко (до 77 \%).

Для определения форм нахождения состава фазовых кристаллических соединений выполнен рентгенографический качественный, полуколичественный фазовый анализы. Анализ

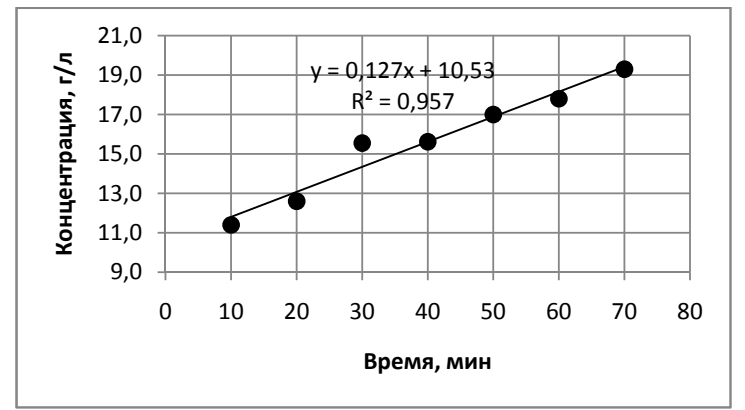

Рис. 1. Зависимость концентрации фтора в растворе, перешедшего из хвостов флотации, от времени выщелачивания 


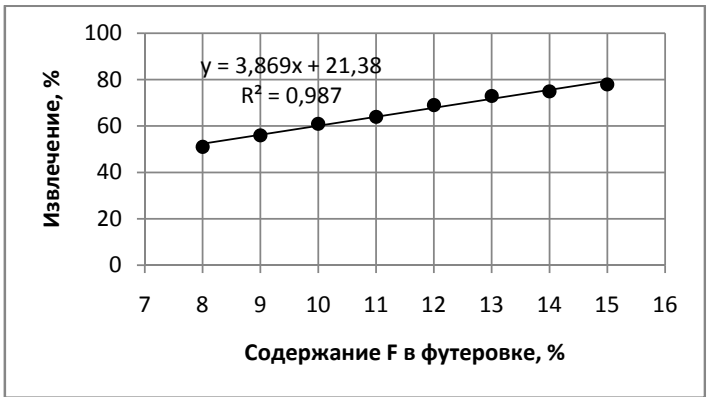

Рис. 2. Зависимость извлечения фтора в раствор от его содержания в угольной футеровке

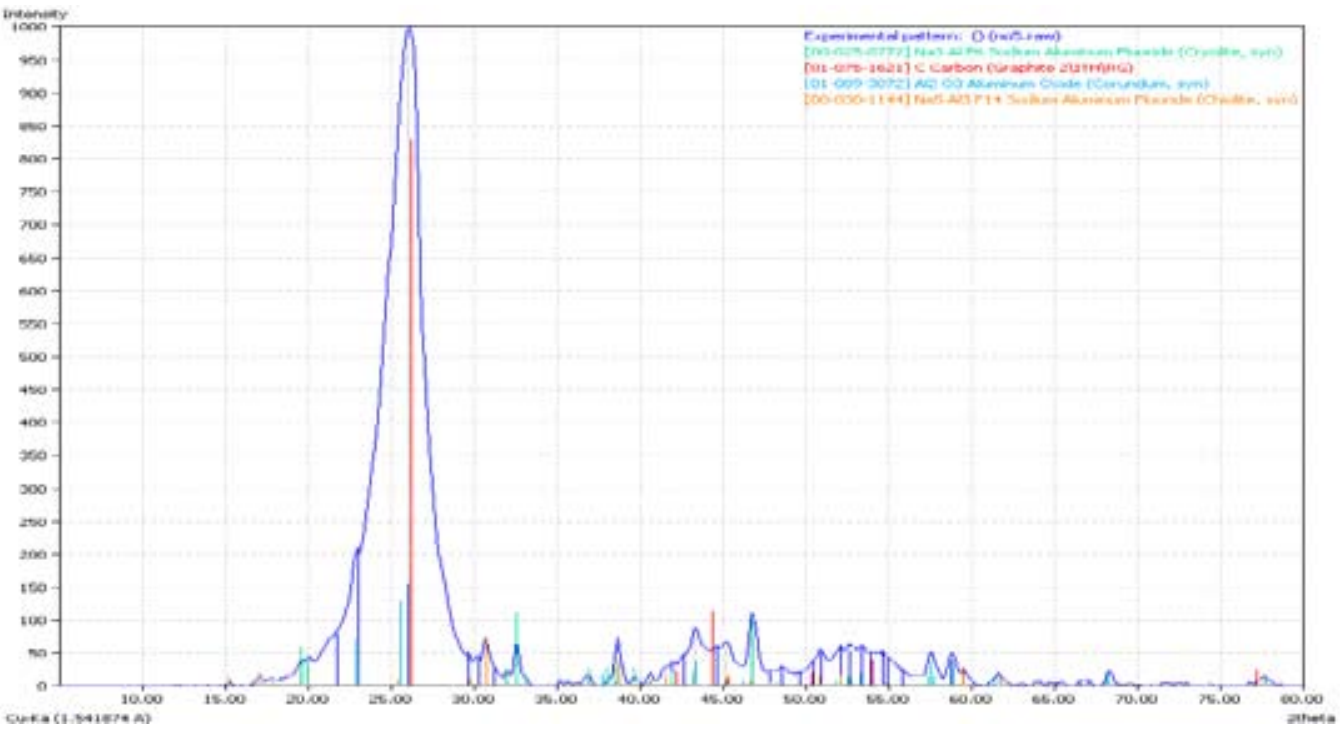

Рис. 3. Дифрактограмма образца хвостов флотации угольной пены до выщелачивания

выполнен на автоматическом порошковом дифрактометре XRD-7000 SHIMADZU лаборатории ФТИ ИрГТУ. Значения по оси X - угол поворота счетчика, по оси $\mathrm{Y}$ - интегральная интенсивность. Цифры на пиках - межплоскостное расстояние линий в ангстремах А̊. Прибор - автоматический порошковый дифрактометр XRD-7000 SHIMADZU.

Анализ выполнен с применением автоматического порошкового дифрактометра XRD7000 SHIMADZU в лаборатории физико-технического института НИУ ИрГТУ. На образцах остатка угольной футеровки после выщелачивания рентгенографический качественный, полуколичественный фазовый анализы не выполнялись.

На рис. 3 и 4 соответственно представлены дифрактограммы образцов хвостов флотации до проведения выщелачивания и после.

В первой пробе были обнаружены кристаллические фазы: криолит (7,95\% $\left.\mathrm{Na}_{3} \mathrm{AlF}_{6}\right)$, $87,02 \%$ графит, оксид алюминия (корунд 1,22\% $\left.\mathrm{Al}_{2} \mathrm{O}_{3}\right)$, хиолит $\left(7,7 \% \mathrm{Na}_{5} \mathrm{Al}_{3} \mathrm{~F}_{14}\right)$.

Во второй пробе обнаружены кристаллические фазы: оксид алюминия (корунд $1,7 \mathrm{Al}_{2} \mathrm{O}_{3}$ ); криолит (0,94 \% $\left.\mathrm{Na}_{3} \mathrm{AlF}_{6}\right)$; углерод (97,01 \% графит), фторид кальция (0,35 \% $\left.\mathrm{CaF}_{2}\right)$. 


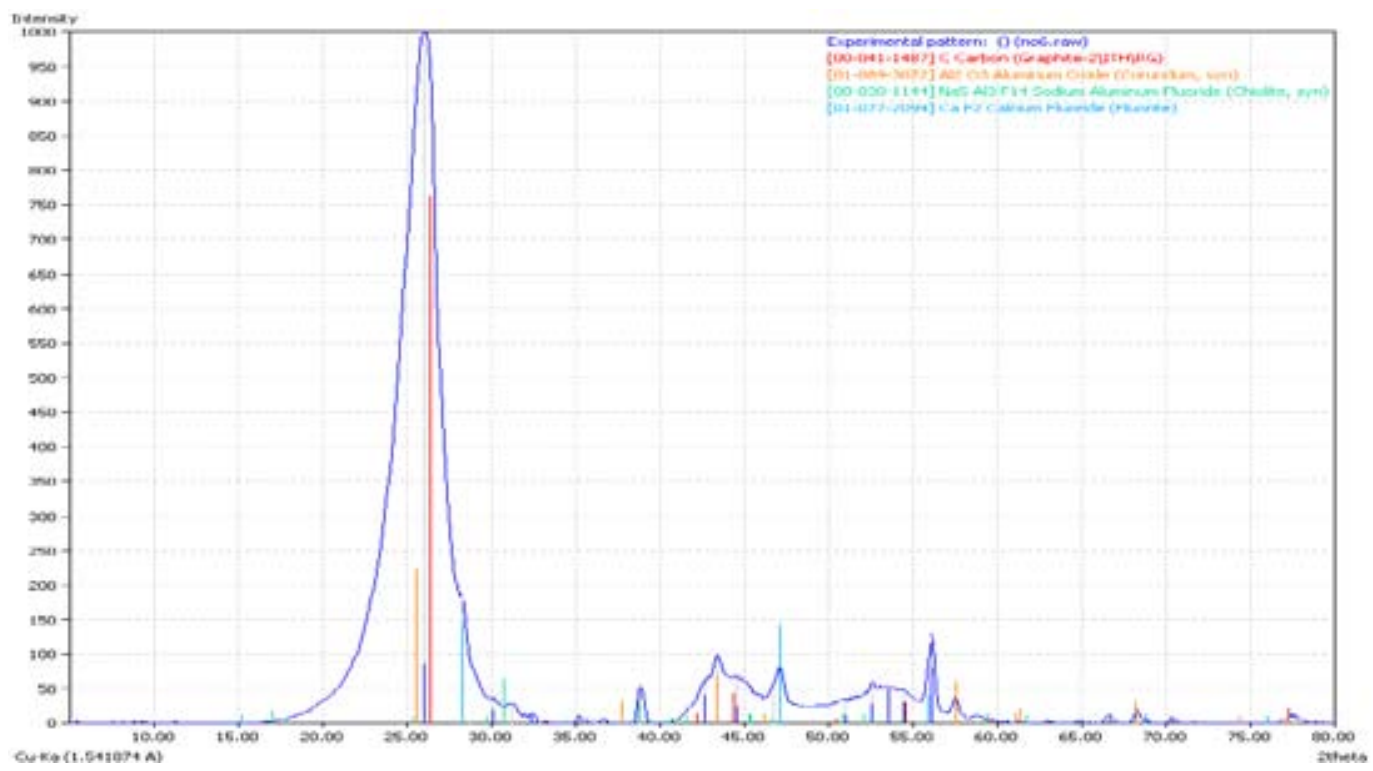

Рис. 4. Дифрактограмма образца хвостов флотации угольной пены после выщелачивания $2 \% \mathrm{NaOH}$

Таким образом, можно извлекать из данных отходов как фториды, так и твердый остаток после выщелачивания с высоким содержанием углерода графитовой структуры, который можно использовать в других отраслях промышленности.

В данный момент на алюминиевом заводе отходы, образующиеся после флотации (хвосты флотации), размещаются на шламохранилище. Предлагается внедрить технологическую схему безотходной технологии (рис. 5), которая позволит дополнительно получить более 1000 т/год фторидов и около 10000 т/год углеродсодержащего концентрата с графитовой структурой. Переработка фторуглеродсодержащих отходов алюминиевого производства даст возможность снизить негативную нагрузку на окружающую среду, что выгодно с точки зрения экологии, экономии площадей и платы за размещение отходов.

Разработанную на БрАЗе технологию можно применять для процесса регенерации фтора из растворов, полученных после обработки твердых отходов электролизного производства каустической содой с заданной концентрацией. Это подтверждается результатами совместных исследований ДТиТРАП ООО «РУСАЛ ИТЦ» в г. Братске с Иркутским государственным техническим университетом. Дальнейшее сотрудничество направлено на поиск и разработку безотходной технологии остальных фторуглеродсодержащих отходов, образующихся в процессе производства алюминия (шлам и пыль газоочистки). 


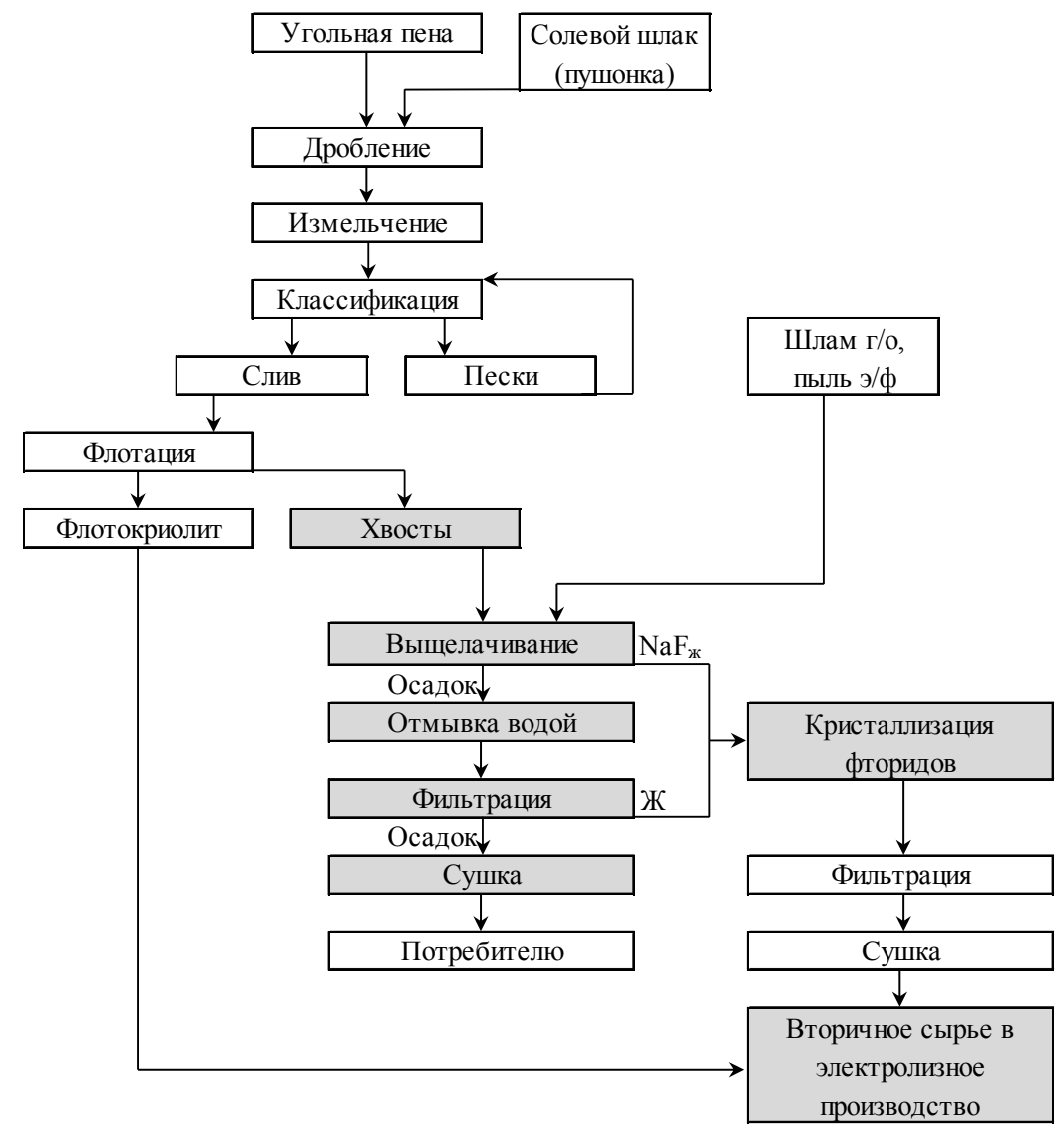

Рис. 5. Предлагаемая схема утилизации отходов на ОАО «РУСАЛ Братск»

\section{Список литературы}

[1] Зельберг Б.И., Рагозин Л.В., Баранщев А.Г. и др. Справочник металлурга. Производство алюминия и сплавов на его основе. 2-е изд., испр. и перераб. СПб.: Изд-во МАНЭБ, 2013. 676 с.

[2] Филиппов С.В., Баранов А.Н., Волянский В.В. и др. Способ получения фторида кальция: Пат. 2487082 РФ (2013) / Б. И. 2013. № 19.

[3] Кондратьев В.В., Афанасьев А.Д., Ржечиикий А.Э. и др. Пат. 2429198 РФ (2011) / Б. И. 2011. № 26.

[4] Баранов А.Н., Гавриленко Л.В., Гавриленко А.А. и др. Регенерация фтора из растворов газоочистки производства алюминия с получением фторида кальция // Вестник ИрГТУ. 2014. №1 (84). С. $75-80$. 